\title{
Politique
}

Politique

\section{Huguette Bouchardeau, Un coin dans leur monde, Paris, Syros, 1980, 135 p.}

\section{Anne-Marie Gingras}

Numéro 5, hiver 1984

Femmes et pouvoir

URI : https://id.erudit.org/iderudit/040453ar

DOI : https://doi.org/10.7202/040453ar

Aller au sommaire du numéro

\section{Éditeur(s)}

Société québécoise de science politique

ISSN

0711-608X (imprimé)

1918-6584 (numérique)

Découvrir la revue

Citer ce compte rendu

Gingras, A.-M. (1984). Compte rendu de [Huguette Bouchardeau, Un coin dans leur monde, Paris, Syros, 1980, 135 p.] Politique, (5), 146-148.

https://doi.org/10.7202/040453ar d'utilisation que vous pouvez consulter en ligne.

https://apropos.erudit.org/fr/usagers/politique-dutilisation/ 
Huguette Bouchardeau, Un coin dans leur monde, Paris, Syros, $1980,135 \mathrm{p}$.

Trois ans avant sa nomination en tant que Secrétaire d'État chargée de l'environnement et de la qualité de la vie (mars 1983), la Française Huguette Bouchardeau a écrit Un coin dans leur monde. Témoignage vivant de son expérience militante au Parti Socialiste Unifié, son volume constitue une réflexion critique des pratiques politiques, telles que vues par une femme, réflexion qui conduit à se demander: Existe-t-il une manière-femme de faire de la politique? Madame Bouchardeau se penche aussi sur l'organisation qu'est le P.S.U., le moins mauvais outil pour faire de la politique en France, selon elle.

Les hommes et les femmes ayant chacun des façons différentes d'aborder le travail, la famille, les enfants, etc..., il n'est pas surprenant qu'ils aient en face des pratiques politiques des regards bien dissemblables. Là où les hommes se permettent des discours grandiloquents et totalisateurs, les femmes se sentent mal à l'aise; 
elles sont plus pragmatiques, elles prennent les choses par «le petit bout de la lorgnette». Car voyez-vous, «la pratique journalière du torchon et de la casserole nous a habituées à plus de modestie» (p. 38).

Le malaise des femmes en politiques, qu'Huguette Bouchardeau analyse brillament, existe bel et bien, même pour une femme comme Simone Veil; au faîte de sa popularité, elle déclare se sentir peu sûre d'elle-même. À capacités égales, c'est l'homme qui ose se lancer en politique; il reste quelque chose, même à la plus talentueuse des femmes, de l'éducation qu'elle a subie... le sentiment qu'elle ne sera peut-être pas à la hauteur. Sentiment d'incapacité, donc, auquel s'ajoute la culpabilité que ressent toute femme qui a un mari et des enfants. On n'expliquera jamais assez à des hommes quelle est cette fameuse «culpabilité féminine» de n'être pas à la maison quand le mari et les enfants arrivent, ont faim, ou réclament des vêtements propres. Doit-on souligner ici que la traditionnelle division des rôles au cœur de la société est en cause...

Malgré cela, les femmes entrent de plus en plus en politique, et il est de bon ton pour toute organisation d'avoir quelques femmes. Pas n'importe où cependant. Quand elles restent au bas de l'échelle, les femmes sont très appréciées. Mais plus elles s'approchent des postes de pouvoir et de responsabilité, plus elles causent des problèmes aux hommes. Huguette Bouchardeau décrit son malaise dans l'action politique; puisque l'entrée des femmes qui ont des préoccupations féministes en politique est révolutionnaire, puisqu'elle signifie modifier les pratiques, faire sauter les normes, comment, dans ce cas, être tranquilles et rassurées? S'il faut changer la manière de faire de la politique, c'est que même le discours de gauche, plus progressiste en apparence que celui de droite à l'égard des femmes, ne colle pas à leurs préoccupations, à leurs problèmes, à ce qu'elles sont, tout simplement. 
Les femmes du courant «G» du Parti Socialiste français (Metz, avril 1979) ont clairement exprimé le problème de la gauche avec les femmes; alors qu'il existe une pensée de droite sur les femmes qui leur donne une place valorisée, sécurisée la famille - , la gauche ne sait comment concevoir le rôle des femmes dans la société. Ce n’est pas avec des résolutions «raccrochées» aux textes à toute vapeur ou l'inclusion du groupe «Femmes» parmi les jeunes, les vieux, les assistés sociaux comme "groupes spécifiques» qui aideront quoi que ce soit.

Ces réflexions, de même que celles qui portent sur l'hypersensibilité au sexisme, sur les ressemblances entre racisme et sexisme, sur la hiérarchie dans les organisations de gauche et les mécanismes de la vie politique (importance du discours, rituels, rapports de pouvoir, luttes...) jalonnent le texte écrit dans un style vivant, direct et sans prétention, à l'image de ce que sont les femmes en politique.

Sans prétendre connaître la panacée aux problèmes des femmes en politique, Huguette Bouchardeau croit que puisque les partis politiques constituent encore, et pour longtemps, les lieux d'intervention privilégiée en ce qui concerne les problèmes du pouvoir, les femmes doivent y entrer nombreuses, liées à des groupes de femmes et conscientes des écueils de la récupération.

À passer, tout au long du livre, du rapport des femmes en politique à l'organisation du P.S.U., l'auteure d'Un coin dans leur monde risque de décourager ceux et celles qui ne s'intéressent qu'aux femmes ou qu'au P.S.U.; mais c'était là un risque assumé. Après tout, n'est-ce pas Huguette Bouchardeau qui dit que les femmes n'excellent pas dans les grands discours décrochés de la réalité... 